animals moving to high altitudes and thus the stimulation of uroporphyrinogen formation would be small. Nevertheless, it is known that increased haemopoiesis on acclimatization to high altitude is a slow process (cf. Grant \& Root, 1952), and small changes in the rate of porphyrin synthesis, maintained for several weeks, could well lead to the observed blood haemoglobin concentrations.

Krebs (1959) has pointed out that, though biochemical and hormonal control mechanisms both operate in higher animals, metabolic regulation at the biochemical level assumes great importance in bacteria, which contain no hormones. It is thus conceivable that the regulation by oxygen of haem biosynthesis, described above, may play a part in the changes in haemoprotein concentrations during respiratory adaptation in micro-organisms. Using Aerobacter aerogenes, Moss (1956) has shown that the maximum cell content of cytochrome $a_{2}$ is obtained when the oxygen concentration in the bacterial culture during growth is $1 \mu \mathrm{M}$. Above and below this concentration the cytochrome $a_{2}$ content of the cell falls off in a manner similar to that found for protohaem formation in vitro (Falk et al. 1959).

\section{SUMMARY}

1. The effects of oxygen concentration on porphyrin biosynthesis from $\delta$-aminolaevulic acid and porphobilinogen have been studied in whole haemolysates of chicken erythrocytes and in supernatants from these preparations.

2. These studies show that concentrations of oxygen higher than $5-7 \%(v / v)$ inhibit the con- version of porphobilinogen into uroporphyrinogen. This inhibition can be reversed by lowering the concentration of oxygen.

3. The stability of uro-, copro- and protoporphyrins to high concentrations of oxygen has been demonstrated.

\section{REFERENCES}

Bailey, S. W. (1954). J. sci. Instrum. 31, 93.

Dresel, E. I. B. (1955). Ciba Found. Symp.: Porphyrin Biosynthesis and Metabolism. p. 72. Ed. by Wolstenholme, G. E. W. \& Millar, E. C. P. London: J. and A. Churchill Ltd.

Dresel, E. I. B. \& Falk, J. E. (1956a). Biochem. J. 63, 72. Dresel, E. I. B. \& Falk, J. E. $(1956 b)$. Biochem. J. 63, 80. Dresel, E. I. B. \& Falk, J. E. (1956c). Biochem. J. 63, 388.

Falk, J. E., Dresel, E. I. B. \& Rimington, C. (1953). Nature, Lond., 172, 292.

Falk, J. E., Porra, R. J., Brown, A., Moss, F. \& Larminie, H. E. (1959). Nature, Lond., 184, 1217.

Gibson, K. D., Laver, W. G. \& Neuberger, A. (1958). Biochem. J. 68, 17 P.

Gordon, A. S. (1959). Physiol. Rev. 39, 1.

Granick, S. \& Mauzerall, D. (1958). Fed. Proc. 17, 233.

Grant, W. C \& Root, W. S. (1952). Physiol. Rev. 32, 449.

Green, S. \& Mazur, A. (1956). Science, 124, 1150.

Krebs, H. (1959). Ciba Found. Symp.: The Regulation of Cell Metabolism, p. 1. Ed. by Wolstenholme, G. E. W. \& O'Connor, C. M. London: J. and A. Churchill Ltd.

Moss, F. (1956). Aust. J. exp. Biol. med. Sci. 34, 395.

Porra, R. J. \& Falk, J. E. (1961). Biochem. biophys. Res. Commun. 5, 179.

Porra, R. J. \& Falk, J. E. (1964). Biochem. J. 90, 69.

Porra, R. J. \& Jones, O. T. G. (1963). Biochem. J. 87, 181.

Sano, S. \& Granick, S. (1961). J. biol. Chem. 236, 1173.

Biochem. J. (1964) 90, 69

\title{
The Enzymic Conversion of Coproporphyrinogen III into Protoporphyrin IX
}

\author{
By R. J. PORRA AND J. E. FALK \\ Division of Plant Industry, C.S.I.R.O., Canberra, A.C.T., Australia
}

(Received 6 May 1963)

Neve, Labbe \& Aldrich (1956) were the first to demonstrate that the true tetrapyrrole intermediates in the biosynthesis of protoporphyrin IX were not porphyrins but hexahydroporphyrins (porphyrinogens) (see Fig. 3). The enzyme system converting coproporphyrinogen III into protoporphyrin IX has been obtained in soluble form from liver mitochondria (Sano, 1958; Sano \& Granick, 1961; Porra \& Falk, 1961; Rimington \& Tooth, 1961; Porra, 1962) and has been partly purified by Sano \& Granick (1961). For the purposes of the present paper it is presumed that the protoporphyrin formed is isomer IX.

The conversion of coproporphyrinogen III into protoporphyrin IX involves the oxidative decarboxylation of two propionic acid side chains to vinyl groups; the enzyme system catalysing this oxidative decarboxylation has been called coproporphyrinogen oxidative decarboxylase (coprogenase) by Porra \& Falk (1961). Although the 
product of this enzymic reaction would presumably be protoporphyrinogen IX, the formation of this compound has not previously been demonstrated. Evidence for the existence in rat-liver mitochondria of a protoporphyrinogen oxidase that oxidizes protoporphyrinogen IX to protoporphyrin IX has, however, been presented by Sano \& Granick (1961). In the present paper it is shown that a reduced form of protoporphyrin IX, probably protoporphyrinogen IX, is indeed formed during the enzymic conversion of coproporphyrinogen III into protoporphyrin IX by a soluble enzyme system from ox-liver mitochondria, which contains coprogenase and probably protoporphyrinogen oxidase also. It should be pointed out that the evidence for the separate existence of these two enzymes is presumptive, since neither has been isolated in the absence of the other.

Porra \& Falk (1961) reported the formation of protein-bound porphyrins during coprogenase activity. These complexes could be hydrolysed by hydrochloric acid to yield both a tetracarboxylic and a dicarboxylic porphyrin. Some of the properties of these free porphyrins are reported below. In addition, the porphyrin-specificity of coprogenase has been studied.

\section{EXPERIMENTAL}

\section{Materials}

Electron acceptors. FAD and phenazine methosulphate were supplied by the Sigma Chemical Co., St Louis, Mo., U.S.A. Cytochrome $c$ (from horse heart) was obtained from Boehringer und Soehne, Mannheim, Germany. 2,6Dichlorophenol-indophenol and methylene blue were obtained from British Drug Houses Pty Ltd.

Hydrochloric acid solutions. The concentrations of these solutions are expressed as $\%(w / v)$ to conform with the ' $\mathrm{HCl}$ number' convention used in this field (cf. Lemberg \& Legge, 1949).

Porphyrins. Many of the porphyrins were prepared from the corresponding methyl esters by hydrolysis with $\mathrm{HCl}$ (cf. Falk, 1961). The methyl esters of coproporphyrins I and III were those described by Falk \& Benson (1953). Monohydroxyethylmonovinyldeuteroporphyrin IX and the trimethyl ester of deuteroporphyrin IX-4-acrylic acid were gifts from Mr J. Barrett, Royal North Shore Hospital, Sydney, Australia. Mesoporphyrin IX (chromatographically pure grade) was supplied by Fluka A.-G., Basel, Switzerland. Protoporphyrin IX was prepared from protohaemin as described by Porra \& Jones $(1963 a)$. Coproporphyrin IV tetramethyl ester (Morsingh \& MacDonald, 1960) and uroporphyrin II octaethyl ester (MacDonald \& Michl, 1956) were gifts from Dr S. F. MacDonald, National Research Council, Ottawa, Canada. Coproporphyrin II was prepared from uroporphyrin II octaethyl ester by the method of Arsenault, Bullock \& MacDonald (1960).

Preparation of deuteroporphyrin IX-4-propionic acid. Deuteroporphyrin IX-4-acrylic acid was dissolved in $0.2 \mathrm{~N}-\mathrm{NH}_{3}$ (approx. $20 \mu \mathrm{m}$-moles $/ \mathrm{ml}$ ) and reduced with sodium amalgam under $\mathrm{O}_{2}$-free $\mathrm{N}_{2}$ in a vessel covered with aluminium foil to exclude light. The porphyrinogen solution formed was removed from the sodium amalgam by filtration and neutralized with acetic acid. The porphyrinogen was then oxidized by titration with aq. $0.5 \mathrm{~N}-\mathrm{I}_{2}$ till a faint straw colour persisted; the excess of iodine was quickly removed by the addition of cysteine. The porphyrin was then extracted at $\mathrm{pH} 4$ into ether in which it was found to have an aetio-type spectrum (relative band intensities IV > III > II > I) with maxima at 399 , 499, 534, 569 and $623 \mathrm{~m} \mu$; the original acrylic acid derivative has a rhodo-type spectrum (III > IV > II > I) with maxima at $412,505,544.5,575$ and $637 \mathrm{~m} \mu$. The change from rhodo-type to aetio-type spectrum with concurrent shift of the maxima to shorter wavelengths shows that the reduction of the porphyrin nucleus to a porphyrinogen was accompanied by the reduction of the acrylic acid group to form a propionic acid side chain (Lemberg \& Falk, 1951). The ether solution was then evaporated to dryness under reduced pressure and the porphyrin stored in an aluminiumfoil-covered vessel at $-15^{\circ}$.

Porphyrinogens. These were prepared by the reduction of the corresponding porphyrin dissolved in $0.2 \mathrm{~N}-\mathrm{NH}_{3}$ with sodium amalgam (Mauzerall \& Granick, 1958) in flasks flushed with $\mathrm{O}_{2}$-free $\mathrm{N}_{2}$ and covered with foil to prevent photochemical oxidation of the porphyrinogens. When the solutions were colourless and no longer fluorescent under ultraviolet light, they were separated from the sodium amalgam, brought to $\mathrm{pH} 7.8$ with acetic acid and diluted with water to $40 \mu \mathrm{m}-\mathrm{moles} / \mathrm{ml}$. A sample of the solution was taken and the porphyrinogen oxidized by titration with aq. $0.5 \mathrm{~N}-\mathrm{I}_{2}$ to the corresponding porphyrin, which was then determined by spectrophotometric measurement of the Soret band. The yield of porphyrinogen, calculated by the difference in porphyrin content before and after treatment with $I_{2}$, varied between 95 and $98 \%$.

Mitochondrial extract. This was prepared from an acetone-dried powder of ox-liver mitochondria as described by Porra \& Falk (1961).

\section{Methods}

Assay of coprogenase activity. The mitochondrial extract was assayed for coprogenase activity by the method of Porra \& Falk (1961), in which all the reduced forms of coproporphyrin III and protoporphyrin IX present after the incubation were oxidized with aq. $\mathrm{I}_{2}$ at $\mathrm{pH} \mathrm{7 \cdot 4}$ to the corresponding porphyrins before acidifying with $\mathrm{HCl}$ and removing the precipitated protein by centrifuging. Solution of the following simultaneous equations, in which the constants represent the $\epsilon_{\mathrm{mM}}$ of copro- and proto-porphyrins at 401.5 and $408 \mathrm{~m} \mu$ in $5 \% \mathrm{HCl}$, permits the determination of both copro- and proto-porphyrins in the one acidified extract:

$$
\begin{gathered}
E_{401 \cdot 5}^{1 \mathrm{~cm}}=408 \text { [coproporphyrin III] } \\
+191[\text { protoporphyrin IX] } \\
E_{408}^{1 \mathrm{~cm} .}=235 \text { [coproporphyrin III] } \\
+275[\text { protoporphyrin IX] }
\end{gathered}
$$

This method of assay is accurate only when the protoporphyrin IX in the acidified extract represents at least $3.5 \%$ of the substrate added. As the reduced porphyrins and the porphyrins formed from them by oxidation during the incubation are estimated together in the porphyrin form, the assay measures coprogenase activity only and not that of protoporphyrinogen oxidase. 
Separation of porphyrins present after incubation. The conversion of propionic acid side chains into vinyl groups decreases the number of carboxyl groups/molecule of the porphyrin, increases its $\mathrm{HCl}$ number and shifts the Soret maxima of the acid and neutral spectra to longer wavelengths (Lemberg \& Legge, 1949). The following procedure makes use of these differences to isolate and identify any vinyl-substituted porphyrins.

The $\mathrm{HCl}$ extract of the incubation mixture was adjusted to $\mathrm{pH} 4$ with sodium acetate and the porphyrins were extracted into ether which was washed with water until free of acetic acid. Porphyrins with low $\mathrm{HCl}$ numbers were then extracted from the ether with $0.1 \% \mathrm{HCl}$ and those with higher $\mathrm{HCl}$ numbers with $5 \% \mathrm{HCl}$. The porphyrins from each of these extracts were then extracted back into ether at $\mathrm{pH} 4$ and small quantities of these solutions were chromatographed, on papers developed with 2,6-lutidinewater, to indicate the number of carboxyl groups/molecule (Falk, Dresel, Benson \& Knight, 1956). Coproporphyrin III and mesoporphyrin IX were used as markers. The remaining porphyrins in the ether solutions were then extracted with $5 \% \mathrm{HCl}$ and their Soret maxima determined in a Beckman model DU spectrophotometer.

\section{RESULTS}

\section{Assay of coprogenase activity}

Effect of iodine on vinyl-substituted porphyrins. Sano \& Granick (1961) found that, under their conditions, oxidation of protoporphyrinogen IX to the porphyrin level with iodine caused degradation of the vinyl side chains; they suggested that the oxidation to protoporphyrin is better achieved photochemically. The details of their iodine treatment were not given.

The assay described above (see the Methods section) has been used to study coprogenase activity in mitochondrial extracts (Porra \& Falk, 1961). As shown below (Fig. 2), the mitochondrial extract converts coproporphyrinogen III into protoporphyrin IX and an intermediate reduced form of protoporphyrin IX. That this reduced derivative of protoporphyrin can be oxidized by treatment with iodine at $\mathrm{pH} \mathbf{7 \cdot 4}$, without causing degradation of the vinyl side chains, is shown in the following experiments. The reduced porphyrins, present at the end of incubations of the mitochondrial extract with coproporphyrinogen III in air as described in Fig. 1, were oxidized to porphyrins either with iodine or by exposure to air and light (Sano \& Granick, 1961). After each treatment the mixtures of porphyrins so formed were esterified and chromatographed on papers developed with kerosene-propanol (Chu, Green \& Chu, 1951) and kerosene-tetrahydropyrane-methyl benzoate (Chu \& Chu, 1954); coproporphyrin III tetramethyl ester and protoporphyrin IX dimethyl ester were used as markers. The chromatograms in both solvent systems revealed the presence of esters of copro- and proto-porphyrins only, indi- cating that vinyl side chains are unaffected by either method of oxidation. Protoporphyrin subsequently isolated by ether-hydrochloric acid fractionation had a Soret maximum at $408 \mathrm{~m} \mu$ in $5 \%$ hydrochloric acid, identical with that of pure protoporphyrin IX.

Effect of oxygen. The effect of oxygen concentration on coprogenase activity was studied to find out whether the incubations in air (Porra \& Falk, 1961) were performed under optimum conditions and also because it is known that oxygen concentration is important in the regulation of tetrapyrrole biosynthesis (cf. Falk \& Porra, 1964). The effect of oxygen concentration on coprogenase activity is shown in Fig. 1; coproporphyrinogen III was not converted into protoporphyrin IX under anaerobic conditions, confirming the findings of Falk, Dresel \& Rimington (1953), Granick \& Mauzerall (1958), Sano \& Granick (1961) and Porra \& Falk (1961). Maximal formation of protoporphyrin IX occurred when the oxygen concentration was $20 \%(\mathrm{v} / \mathrm{v})$. The inhibition observed at higher oxygen concentrations is not due to the oxidation of coproporphyrinogen III to coproporphyrin III, which is not utilized by the enzyme, since experiments performed under the same conditions but in the absence of the enzyme preparation showed that the formation of coproporphyrin III from coproporphyrinogen III was no faster in oxygen than in air. The rate of formation of a pink partly-oxidized derivative of coproporphyrinogen

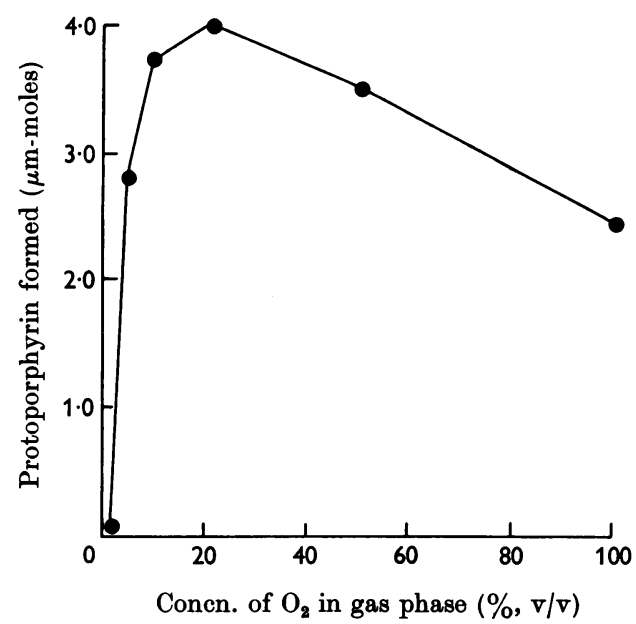

Fig. 1. Effect of oxygen concentration on coprogenase activity. Mitochondrial extract $(0.4 \mathrm{ml}$.) was incubated at $37^{\circ}$ for $30 \mathrm{~min}$. with $15 \mu \mathrm{m}$-moles of coproporphyrinogen III, $50 \mu$ moles of GSH and $100 \mu$ moles of potassium phosphate at $\mathrm{pH} \mathrm{7.4}$, in a final volume of $3.9 \mathrm{ml}$. Incubations were performed in foil-covered flasks stoppered with Bunsen valves under mixtures of $\mathrm{O}_{2}$ and $\mathrm{N}_{2}$ supplied by the constant-flow apparatus of Bailey (1954). 


\section{Table 1. Stability of coproporphyrinogen in the presence of oxidants}

Coproporphyrinogen $(10 \mu \mathrm{m}$-moles) was incubated in vacuo in Thunberg cuvettes with $200 \mu \mathrm{m}$-moles of potassium phosphate at $\mathrm{pH} 7.4$ for $20 \mathrm{~min}$. at $20^{\circ}$ in a final volume of $4.5 \mathrm{ml}$. with the additions shown. Coproporphyrinogen oxidation was determined in most experiments by spectrophotometric measurement of the appearance of the Soret band of coproporphyrin at $399 \mathrm{~m} \mu\left(\epsilon_{\mathrm{mM}}=171\right)$ against controls containing no oxidant. When cytochrome $c$ and methylene blue were used, however, reduction of these electron acceptors was followed spectrophotometrically at $550 \mathrm{~m} \mu$ and $615 \mathrm{~m} \mu$ respectively against controls containing no coproporphyrinogen; the $\epsilon_{\mathrm{mM}}^{550 \mathrm{~m} \mu}$ for the difference (reduced minus oxidized) spectrum of cytochrome $c$ used was $19 \cdot 8$ (cf. Morton, 1958).

$\begin{array}{lccc}\text { Amount of } & \begin{array}{c}\text { Copropor- } \\ \text { oxidant used } \\ (\mu \mathrm{m}-\mathrm{moles})\end{array} & \begin{array}{c}E_{0}^{\prime}(\mathrm{pH}) \\ (\mathrm{mv})\end{array} & \begin{array}{c}\text { phyrinogen } \\ \text { oxidized } \\ (\%)\end{array} \\ \text { Oxidant } & 200 & -0 \cdot 180 & 0 \\ \text { blue } & 50 & +0 \cdot 011 & 0 \\ \text { e methosulphate } & 50 & +0 \cdot 080 & 0 \\ \text { orophenol-indophenol } & 100 & +0 \cdot 217 & 0 \cdot 36 \\ \text { chrome } c & 50 & +0 \cdot 263 & 4 \cdot 56 \\ \text { m ferricyanide } & 100 & +0 \cdot 49 & 44 \cdot 3\end{array}$

III was, however, increased in oxygen. This pink derivative is probably tetrahydrocoproporphyrin III since it absorbs strongly at $500 \mathrm{~m} \mu$ but not at $450 \mathrm{~m} \mu$ (Mauzerall, 1962). The effect of this substance on coprogenase activity is not known.

Alternative electron acceptors. The compounds shown in Table 1 were tested in the coprogenase system as possible alternative electron acceptors to oxygen. These enzymic reactions were carried out in vacuo in the absence of GSH. In no case was protoporphyrin detected. This was not due to the oxidation of coproporphyrinogen III to coproporphyrin III by the various electron acceptors, since, in experiments under the same conditions but in the absence of the enzyme, only potassium ferricyanide caused rapid oxidation of coproporphyrinogen III.

\section{Detection of reduced forms of protoporphyrin}

The reduction of the porphyrin nucleus to that of the hexahydroporphyrin (porphyrinogen) involves the intermediate formation of dihydro- and tetrahydro-porphyrins. All these reduced porphyrins lack the Soret band characteristic of the parent porphyrin (Mauzerall \& Granick, 1958; Mauzerall, 1962). This spectroscopic difference was used by Hoare \& Heath (1958) to demonstrate the formation of uroporphyrinogen from porphobilinogen by extracts of Rhodopseudomonas spheroides and has been employed in the following procedure to detect the formation of a reduced derivative of protoporphyrin.

Mitochondrial extract was incubated with coproporphyrinogen III as described in Fig. 2. At the end of the incubation the iodine treatment was omitted and the reaction was stopped by the addition of $0.6 \mathrm{ml}$. of conc. hydrochloric acid followed by $16.0 \mathrm{ml}$. of $5 \%$ hydrochloric acid. This mixture was quickly transferred to a centrifuge

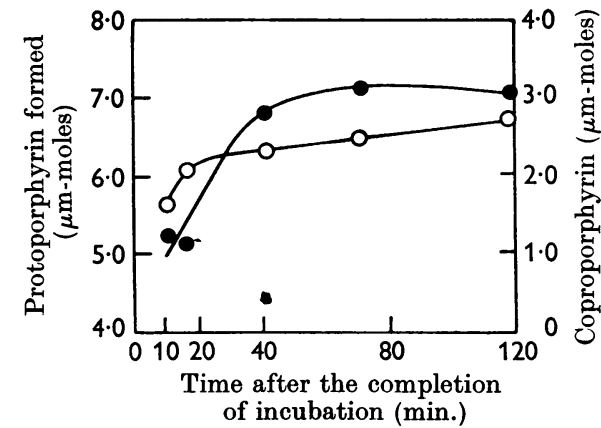

Fig. 2. Detection of a reduced form of protoporphyrin. Mitochondrial extract $(2 \cdot 0 \mathrm{ml}$.) was incubated with $30 \mu \mathrm{m}$ moles of coproporphyrinogen III for $20 \mathrm{~min}$. under conditions otherwise identical with those in Fig. 1. The photochemical oxidation of coproporphyrinogen and reduced protoporphyrin intermediates, present at the end of the incubation, led to the appearance of coproporphyrin $(O)$ and protoporphyrin (O) which were followed spectrophotometrically (as described in the Methods section).

tube which was flushed with oxygen-free nitrogen and sealed. The protein precipitate was then removed by centrifuging. The supernatant was drawn off through a nitrogen-filled line into an evacuated cuvette and the extinctions were read at 401.5 and $408 \mathrm{~m} \mu$. The first reading was made $10 \mathrm{~min}$. after completion of the incubation. The cuvette was then opened and exposed to air and sunlight, and the photochemical oxidation of the porphyrinogens to porphyrins (Fig. 2) was followed by measuring changes in extinctions at 401.5 and $408 \mathrm{~m} \mu$. The concentrations of copro- and protoporphyrins were calculated from the equations given above. The reduced protoporphyrin present at the time of the first reading (Fig. 2) represented $26.5 \%$ of the total protoporphyrin recovered, and in subsequent experiments as much as $37.5 \%$ was 
found. Since even at the first reading much of the protoporphyrin was in the oxidized (porphyrin) form, the mitochondrial extract apparently contains not only coprogenase but also protoporphyrinogen oxidase.

No attempt was made to extract all the acidsoluble tetrapyrroles because further manipulations would lead to greater oxidation of the reduced porphyrins; the low recovery (Fig. 2) is explained in part by this and in part by the formation of acid-insoluble protein-bound porphyrins (Porra \& Falk, 1961).

\section{Substrate specificity of the mitochondrial extract}

The structures of the various isomers of coproporphyrin and coproporphyrinogen are shown in Fig. 3. The crude extract converted coproporphyrinogen III into protoporphyrin IX but was unable to use coproporphyrinogens I and II or coproporphyrins I and III (cf. Granick \& Mauzerall, 1958; Mauzerall, 1959; Sano \& Granick, 1961; Porra \& Falk, 1961). A small amount of a protoporphyrin was formed from coproporphyrinogen IV. This product had a higher hydrochloric acid number than coproporphyrin IV and on paper chromatograms behaved as a dicarboxylic porphyrin. Like protoporphyrin IX, it had a Soret maximum at $408 \mathrm{~m} \mu$ in $5 \%$ hydrochloric acid, and thus differs from coproporphyrin IV (Soret maximum $401.5 \mathrm{~m} \mu$ ). Possible structures for this porphyrin are discussed below.

Deuteroporphyrinogen IX-4-propionic acid, a tricarboxylic compound (Fig. 3), was also transformed by the mitochondrial extract. The porphyrin obtained had a higher hydrochloric acid number than deuteroporphyrin IX-4-propionic acid, and its chromatographic behaviour suggested the presence of only two carboxyl groups. The Soret maximum in $5 \%$ hydrochloric acid was at 404.5 $\mathrm{m} \mu$, intermediate between that of deuteroporphyrin IX-4-propionic acid $(401.5 \mathrm{~m} \mu)$ with no vinyl groups and protoporphyrin IX $(408 \mathrm{~m} \mu)$ with two vinyl groups, suggesting that this porphyrin is 4-monovinyldeuteroporphyrin.

\section{Acid hydrolysis of protein-bound porphyrins}

After incubating coproporphyrinogen III with coprogenase for short periods and treating the mixture with iodine and hydrochloric acid, Porra \& Falk (1961) detected protein-bound porphyrins, possibly derived from protein-bound porphyrinogens, which may be intermediates in the enzymic formation of protoporphyrin IX. After hydrolysis with hydrochloric acid, two ether-soluble porphyrins were obtained: a tetracarboxylic porphyrin which was extracted from ether by $0.36 \%$ hydrochloric acid and a dicarboxylic porphyrin which was extracted by $5 \%$ hydrochloric acid.

Further studies of the tetracarboxylic porphyrin indicate that it was coproporphyrin III; after esterification in hydrochloric acid-methanol (Falk, 1961) it behaved like an authentic sample of coproporphyrin III tetramethyl ester on chromatograms developed with kerosene-propanol (Chu et al. 1951)

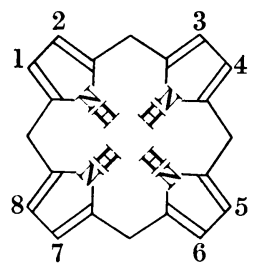

Porphyrinogen nucleus

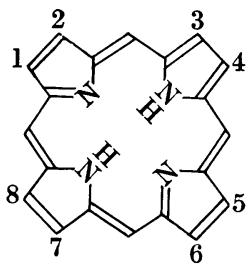

Porphyrin nucleus
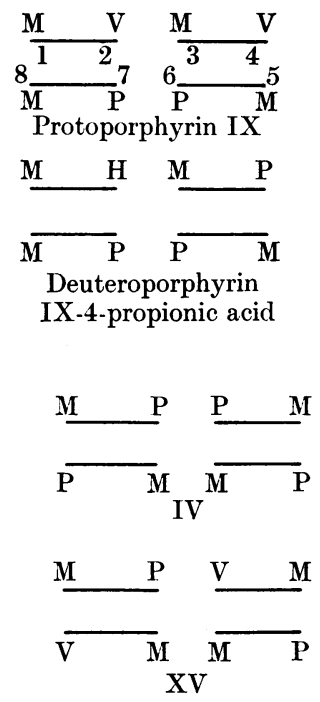
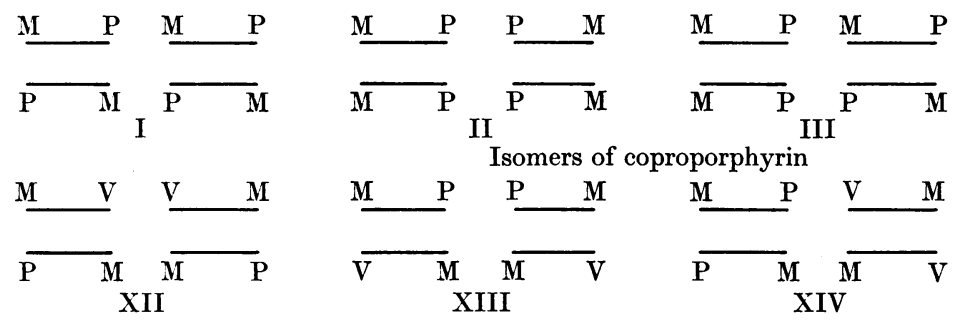

Possible protoporphyrin isomers from coproporphyrinogen IV

Fig. 3. Structures of various tetrapyrroles. The ring structure of porphyrins and porphyrinogens is not indicated in the diagrams which show side-chain positions only. Corresponding porphyrins and porphyrinogens have identical substitution. Side-chain abbreviations: $\mathrm{H},-\mathrm{H} ; \mathrm{M},-\mathrm{CH}_{3} ; \mathrm{P},-\mathrm{CH}_{2} \cdot \mathrm{CH}_{2} \cdot \mathrm{CO}_{2} \mathrm{H} ; \mathrm{V},-\mathrm{CH} \mathrm{CH}_{2}$. 
and kerosene-tetrahydropyrane-methyl benzoate (Chu \& Chu, 1954). The free porphyrin in ether had an aetio-type spectrum with maxima at 396,497 , 528, 572 and $625 \mathrm{~m} \mu$, which resembles that of coproporphyrin III (397, 498, 527, 568 and $623 \mathrm{~m} \mu$ ).

The dicarboxylic porphyrin was esterified and chromatographed by the same two methods. The $R_{F}$ values were lower than those of protoporphyrin IX, mesoporphyrin IX and deuteroporphyrin IX dimethyl esters, higher than those of haematoporphyrin IX dimethyl ester but identical with those of monovinylmonohydroxyethyldeuteroporphyrin IX dimethyl ester. The free porphyrin in ether had an aetio-type spectrum, with maxima at 397, 499, 532, 577 and $630 \mathrm{~m} \mu$, differing from those of mesoporphyrin IX with no vinyl groups (396, 497, 526, 566 and $623 \mathrm{~m} \mu$ ) and protoporphyrin IX with two vinyl groups $(404,503,536,576$ and $633 \mathrm{~m} \mu$ ), but resembling that of monohydroxyethylmonovinyldeuteroporphyrin IX (401, 502, 533, 574 and $628 \mathrm{~m} \mu$ ). Both the chromatographic and spectroscopic evidence suggest, therefore, that this porphyrin is a monovinyl compound resembling monohydroxyethylmonovinyldeuteroporphyrin IX.

\section{DISCUSSION}

Oxygen requirement of coprogenase and the resistance of coproporphyrinogen III to oxidation. The unsuccessful attempt to replace oxygen in the coprogenase reaction with an alternative electron acceptor confirms the suggestion of Sano \& Granick (1961) that molecular oxygen is essential for coprogenase activity in mammalian liver preparations. The stability of porphyrinogens at neutral pH in the absence of light (Mauzerall \& Granick, 1958) is confirmed by the experiments with coproporphyrinogen III (Table 1) which demonstrate in addition that oxidizing agents with redox potentials up to about $+200 \mathrm{mv}$ do not oxidize coproporphyrinogen III.

Detection of reduced protoporphyrin $I X$. Whether or not a reduced form of protoporphyrin IX, such as protoporphyrinogen IX, is formed during the enzymic conversion of coproporphyrinogen III into protoporphyrin IX has for some time been an open question (Bogorad, 1960; Granick \& Mauzerall, 1961; Lascelles, 1962). The present study demonstrates that a reduced form of protoporphyrin IX is formed. It is now well established that the early tetrapyrrole intermediates in the biosynthesis of haem are porphyrinogens, and the reduced form of protoporphyrin IX detected here may well be protoporphyrinogen IX. Porra \& Jones $(1963 a)$ have shown that ferrochelatase preparations from pig liver will catalyse the insertion of $\mathrm{Fe}^{2+}$ ions into porphyrins but not into porphyrinogens. It seems likely, therefore, that the reduced derivative of protoporphyrin IX detected in our incubations must be oxidized to protoporphyrin IX in vivo before protohaem synthesis can take place. There are indications in our work, and in that of Sano \& Granick (1961), that the soluble enzyme preparations from liver mitochondria contain a protoporphyrinogen oxidase.

Substrate specificity of coprogenase in the mitochondrial extract. We find that the substrate specificity of coprogenase is not restricted to coproporphyrinogen III as claimed by Mauzerall (1959). Deuteroporphyrinogen IX-4-propionic acid was attacked by the crude coprogenase preparation. In addition, a small amount of an undefined isomer of protoporphyrin was formed from coproporphyrinogen IV. Four protoporphyrins, isomers XII, XIII, XIV and XV (Fig. 3), are possible products of this reaction. If one assumes, as was found for ferrochelatase (Porra \& Jones, 1963b), that an 'isomer IX' - or 'isomer I'-type attachment occurs between coprogenase and its substrate then protoporphyrin XIII or XIV would be formed by attack on the free propionic acid groups. One cannot distinguish between these isomers.

The transformation of deuteroporphyrinogen IX-4-propionic acid, an unlikely intermediate in protoporphyrin IX formation, is the first demonstration that a tricarboxylic tetrapyrrole can be utilized by coprogenase. This is of interest because it is believed that coproporphyrinogen III is converted into protoporphyrin IX by way of a tricarboxylic compound (Bogorad \& Granick, $1953 a, b$; Falk et al. 1956; Sano \& Granick, 1961).

Porphyrins from protein-bound complexes. Eriksen (1955) has detected a protein-bound protoporphyrin and Sugita (1962) a particle-bound form in which the protoporphyrin may be linked to protein. Both authors have suggested that these bound porphyrins may be intermediates in haem formation. Sano \& Granick (1961) have postulated a pathway for the biosynthesis of cytochrome c which involves an intermediate protein-bound porphyrinogen, formed by an addition reaction between the vinyl groups of protoporphyrinogen IX and two thiol groups of the apo-enzyme. In the protein-bound porphyrins studied in the present work, the porphyrins appear to be linked covalently to the proteins. Porra \& Falk (1961) found that a porphyrin can be split off by the silver salt method of Paul (1950), and a thioether linkage may thus be involved. If the binding is like that in cytochrome $c$, one would expect treatment with hydrochloric acid to hydrolyse peptide linkages and liberate an ether-insoluble porphyrin like porphyrin $c$ (Neilands \& Tuppy, 1960). No porphyrin of this kind was detected, however, and the two ethersoluble porphyrins that were found were probably 
coproporphyrin III and a dicarboxylic monovinylporphyrin. It is possible, therefore, that the porphyrins are attached covalently through their carboxyl groups to the $\epsilon$-amino groups of lysine residues of the protein. The protein-porphyrin complexes may be related to intermediates in the biosynthesis of protoporphyrin IX (Porra \& Falk, 1961). The isolation, after acid hydrolysis of the protein complexes, of a compound with properties similar to those of monohydroxyethylmonovinyldeuteroporphyrin IX is especially interesting in view of the pustulation by Bogorad (1960) that this compound may be an intermediate in protoporphyrin formation.

\section{SUMMARY}

1. A reduced form of protoporphyrin IX, probably protoporphyrinogen IX, is formed during the conversion of coproporphyrinogen III into protoporphyrin IX by a mitochondrial extract. In addition to coprogenase this extract appears to contain protoporphyrinogen oxidase.

2. The mitochondrial extract converts coproporphyrinogen III into protoporphyrin IX, coproporphyrinogen IV into an isomer of protoporphyrin as yet undefined, and deuteroporphyrinogen IX-4-propionic acid into 4-monovinyldeuteroporphyrin. Coproporphyrinogens I and II, and coproporphyrins I and III, are inactive.

3. Acid hydrolysis of the protein-bound porphyrins formed during incubation of the mitochondrial extract with coproporphyrinogen III yielded a tetracarboxylic porphyrin, which appears to be coproporphyrin, and a monovinyl-dicarboxylic porphyrin.

4. Coproporphyrinogen III is readily oxidized by potassium ferricyanide, but is reasonably stable, at $\mathrm{pH} \mathrm{7.4}$ in the dark, in the presence of FAD, methylene blue, phenazine methosulphate, 2,6dichlorophenol-indophenol or oxidized cytochrome $c$.

5. Formation of protoporphyrin IX from coproporphyrinogen III by an extract of ox-liver mitochondria is an oxygen-dependent process. The maximum rate is observed at oxygen concentrations of $20 \%(\mathrm{v} / \mathrm{v})$. Under anaerobic conditions oxygen could not be replaced by FAD, methylene blue, phenazine methosulphate, 2,6-dichlorophenolindophenol or oxidized cytochrome $c$.

\section{REFERENCES}

Arsenault, G. P., Bullock, E. \& MacDonald, S. F. (1960). J. Amer. chem. Soc. 82, 4384.

Bailey, S. W. (1954). J. sci. Instrum. 31, 93.
Bogorad, L. (1960). Symp. Comparative Biochemistry, vol. 1, Comparative Biochemistry of Photoreactive Systems, p. 227. Ed. by Allen, M. B. New York and London: Academic Press Inc.

Bogorad, L. \& Granick, S. (1953a). Proc. nat. Acad. Sci., Wash., 39, 1176.

Bogorad, L. \& Granick, S. (1953b). J. biol. Chem. 202, 793.

Chu, T. C. \& Chu, E. J. (1954). J. biol. Chem. 208, 537.

Chu, T. C., Green, A. A. \& Chu, E. J. (1951). J. biol. Chem. 190, 643.

Eriksen, L. (1955). Ciba Found. Symp.: Porphyrin Biosynthesis and Metabolism. p. 185. Ed. by Wolstenholme, G. E. W. \& Millar, E. C. P. London: J. and A. Churchill Ltd.

Falk, J. E. (1961). J. Chromat. 5, 277.

Falk, J. E. \& Benson, A. (1953). Biochem. J. 55, 101.

Falk, J. E., Dresel, E. I. B., Benson, A. \& Knight, B. C. (1956). Biochem. J. 63, 87.

Falk, J. E., Dresel, E. I. B. \& Rimington, C. (1953). Nature, Lond., 172, 292.

Falk, J. E. \& Porra, R. J. (1964). Biochem. J. 90, 66.

Granick, S. \& Mauzerall, D. (1958). Fed. Proc. 17, 233.

Granick, S. \& Mauzerall, D. (1961). In Metabolic Pathways, p. 525. Ed. by Greenberg, D. M. New York and London: Academic Press Inc.

Hoare, D. S. \& Heath, H. (1958). Nature, Lond., 181, 1592.

Lascelles, J. (1962). In The Bacteria, p. 335. Ed. by Gunsalus, I. C. \& Stanier, R. Y. New York: Academic Press Inc.

Lemberg, R. \& Falk, J. E. (1951). Biochem. J. 49, 674.

Lemberg, R. \& Legge, J. W. (1949). Hematin Compounds and Bile Pigments, pp. 68-76. London and New York: Interscience Publishers Inc.

MacDonald, S. F. \& Michl, K. H. (1956). Canad. J. Chem. 34, 1768.

Mauzerall, D. (1959). Abstr. Pap. Amer. chem. Soc. 135th Meet. p. $54 \mathrm{c}$.

Mauzerall, D. (1962). J. Amer. chem. Soc. 84, 2437.

Mauzerall, D. \& Granick, S. (1958). J. biol. Chem. 232, 1141.

Morsingh, F. \& MacDonald, S. F. (1960). J. Amer. chem. Soc. 82, 4377.

Morton, R. K. (1958). Rev. pure appl. Chem. 8, 161.

Neilands, J. B. \& Tuppy, H. (1960). Biochim. biophys. Acta, 38, 351.

Neve, R. A., Labbe, R. F. \& Aldrich, R. A. (1956). J. Amer. chem. Soc. 78, 691.

Paul, K.-G. (1950). Acta chem. scand. 4, 239.

Porra, R. J. (1962). Ph.D. Thesis: Australian National University, Canberra.

Porra, R. J. \& Falk, J. F. (1961). Biochem. biophys. Res. Commun. 5, 179.

Porra, R. J. \& Jones, O. T. G. (1963a). Biochem. J. 87, 181.

Porra, R. J. \& Jones, O. T. G. (1963b). Biochem. J. 87, 186.

Rimington, C. \& Tooth, B. E. (1961). J. Biochem., Tokyo, 49, 456.

Sano, S. (1958), Acta haematol. jap. 21(2), 337.

Sano, S. \& Granick, S. (1961). J. biol. Chem. 236, 1173.

Sugita, Y. (1962). J. Biochem., Tokyo, 51, 436. 